\title{
Modelling the flux of radionuclides from the Rhone River into the Mediterranean Sea
}

\author{
R. Periáñez \\ Dpto. Física Aplicada 1, EUITA, University of Seville, Ctra Utrera km 1, 41013 Sevilla, Spain \\ e-mail: rperianez@us.es
}

\begin{abstract}
A numerical model has been developed to simulate the input of radionuclides into the Mediterranean Sea through the Rhone River plume. The model is fully 3D. It solves the hydrodynamic equations, which include baroclinic terms and a turbulence model, together with the suspended sediment equations and radionuclide dispersion equations. The suspended sediment sub-model includes four particle classes, settling and deposition. The radionuclide equations include the exchanges of radionuclides between water, suspended sediments and bed sediments, described using a kinetic model. The effect of salinity changes upon uptake kinetics has also been included. Computed water circulation, salinity pattern, suspended sediment distribution and sedimentation rates are in agreement with observations in the area. The model has been applied to simulate the dispersion of ${ }^{137} \mathrm{Cs}$ and ${ }^{239,240} \mathrm{Pu}$ through the plume. Computed specific activities in water, suspended matter and bottom sediments are in agreement with the measured distributions. The model can also be applied to calculate distribution coefficients. Although some water circulation models for the Rhone River plume exist in current literature, this is the first time in which a detailed hydrodynamic and suspended sediment model has been applied to simulate the dispersion of radionuclides in the plume.
\end{abstract}

\section{INTRODUCTION}

A model for simulating the transport of radionuclides in a river plume is briefly described and applied to the Rhone River plume, which introduces radionuclides released to the river into the Mediterranean Sea. The model domain covers the river plume in the coastal area, where salinity changes from freshwater to seawater values. Artificial radionuclides reach the Rhone River through weathering of surface soils contaminated by atmospheric fallout and through the effluents from nuclear facilities: several power plants located along the river course and, mainly, from Marcoule nuclear fuel reprocessing plant (now is not in operation but releases have continued since washing effluents are produced and discharged). In the case of the Rhone, the low mixing of the discharge waters gives place to a well-identified surface plume in which a thin upper layer ( 1 or $2 \mathrm{~m}$ ) is separated from the ambient seawater by a sharp density gradient. This plume extends 20 or $30 \mathrm{~km}$ offshore. Numerical modelling of these plumes is a difficult task that requires the inclusion of density differences in the full 3D hydrodynamic equations. The Rhone River gives the opportunity to test the behaviour of radionuclide dispersion models, including a kinetic approach for the transfers between the liquid and solid phases, when integrated with a detailed hydrodynamic model of a complex oceanographic system as a surface river plume.

The model solves the hydrodynamic equations, including baroclinic terms that account for density variations and a turbulence model, and the suspended matter equations together with the radionuclide dispersion equations. The suspended matter equations include advective/diffusive transport of particles, settling (vertical fall), particle deposition on the seabed and erosion of the sediment. Several suspended matter particle classes are considered since a sensitivity study (1) has indicated that model output is very sensitive to the particle size used in the equations. Exchanges of radionuclides between the liquid and 
solid phases are described in terms of kinetic coefficients. The dependence of kinetic coefficients with water salinity is also included in the model. This is necessary in a river plume where salinity changes from freshwater to seawater values. The model has been applied to simulate the dispersion of ${ }^{137} \mathrm{Cs}$ and ${ }^{239,240} \mathrm{Pu}$ and results have been compared with measurements in the plume.

The model is briefly described in the following section. Next, some examples of results are presented.

\section{MODEL DESCRIPTION}

Water circulation is obtained from the full 3D hydrodynamic equations, including baroclinic terms that account for density gradients. Water density is related with salinity through a standard equation of state and salinity is computed from an advection/diffusion equation with appropriate boundary conditions at the river mouth. A 1-equation turbulence model is applied to determine the vertical eddy viscosity over the model domain.

Four suspended particle classes are considered in the model according to measurements in the plume. Each particle class is governed by an advection/diffusion equation to which the settling, deposition and erosion terms are added. The settling velocity of each particle class is determined from Stokes's law applied to the average particle diameter of each class, as in other suspended sediment models. The deposition rate is written in terms of the settling velocity of particles and their concentration just above the sea bed. The erosion term for each particle class is written using the erodability constant and the fraction of particles of the corresponding class in the bed. Critical erosion and deposition stresses are also used in the conventional form. Sedimentation rates are calculated as the balance between the deposition and erosion terms. The hydrodynamic and suspended sediment model is described in detail in (2). The suspended sediment model provides the suspended matter concentrations over the model domain, as well as the distribution of particle classes over the seabed.

The exchanges of radionuclides between the dissolved and solid phases are described in terms of kinetic transfer coefficients. Thus, assuming that adsorption/release reactions are governed by a single reversible reaction, a coefficient $k_{1}$ governs the transfer from the liquid to the solid phase and a coefficient $k_{2}$ governs the inverse process. Radionuclides in suspended matter and the dissolved phase are transported by advection/diffusion processes and those attached to the solid phase also settle with the settling velocity corresponding to the particle class to which they are fixed. They can also be deposited on the sea bed. The radionuclide dispersion model has been described before (3) in a 3D form and details will not be repeated here (although only one size of particles was considered, this does not affect the essential of the model formulation). The only difference with respect to the original model presented in (3) is the inclusion of the explicit dependence of the kinetic coefficient $k_{1}$ with salinity, that in this application changes from freshwater to seawater values. The coefficient $k_{1}$ depends on salinity as in (4):

$$
\begin{aligned}
& k_{1}=k_{1}^{0}(1-\delta) \\
& \delta=\frac{S}{S+S_{0}}
\end{aligned}
$$

In these equations $k_{1}{ }^{0}$ is the freshwater value of the kinetic coefficient, $S$ is water salinity and $S_{0}$ is the salinity value at which $50 \%$ of saturation occurs (4). It must be noted that as salinity increases, the transfer of radionuclides to the solid phase decreases due to competition effects of radionuclides with ions dissolved in water. The relations given above have been tested through laboratory experiments (4).

The kinetic coefficient $k_{2}$ is considered to be constant and to have the same value for all particle classes. On the other hand, $k_{1}$ also depends on the particle size since depends on the surface of particles per water volume unit (3). More details may also be seen in (5). 
Once the water circulation, salinity distribution, suspended matter distribution for each particle class and distribution of particles in bed sediments are calculated and stored in files, the radionuclide dispersion model may be run using these files as input data. The radionuclide dispersion model consists of 9 equations expressing the time evolution of activity concentrations in the dissolved phase, the 4 suspended particle classes and the 4 bed sediment grain sizes. All equations are solved using explicit finite difference schemes. Spatial resolution of the model is $1 \mathrm{~km}$. A variable grid is used in the vertical to have enough resolution to solve the salinity gradients in the surface plume. Thus 10 layers with thickness $1 \mathrm{~m}$ are used followed by thicker layers increasing to $15 \mathrm{~m}$.

\section{RESULTS AND DISCUSSION}

The model has been initially run for average water discharge and under calm conditions, although the plume is strongly affected by wind conditions. Parameters for the model have been obtained from literature. Details on these parameters and their values are described in detail in $(2,5)$. In these references, it is also justified why different oxidation states for plutonium are not considered and colloids are neglected.

A map showing the total concentration of particles obtained after a computation time of three days can be seen in figure 1 . Measured particle concentrations, from (6,7), are also shown. It can be seen that there is a good agreement between measured and computed suspended particle concentrations. Sedimentation rates have also been calculated, and their values are in agreement with observations (2).

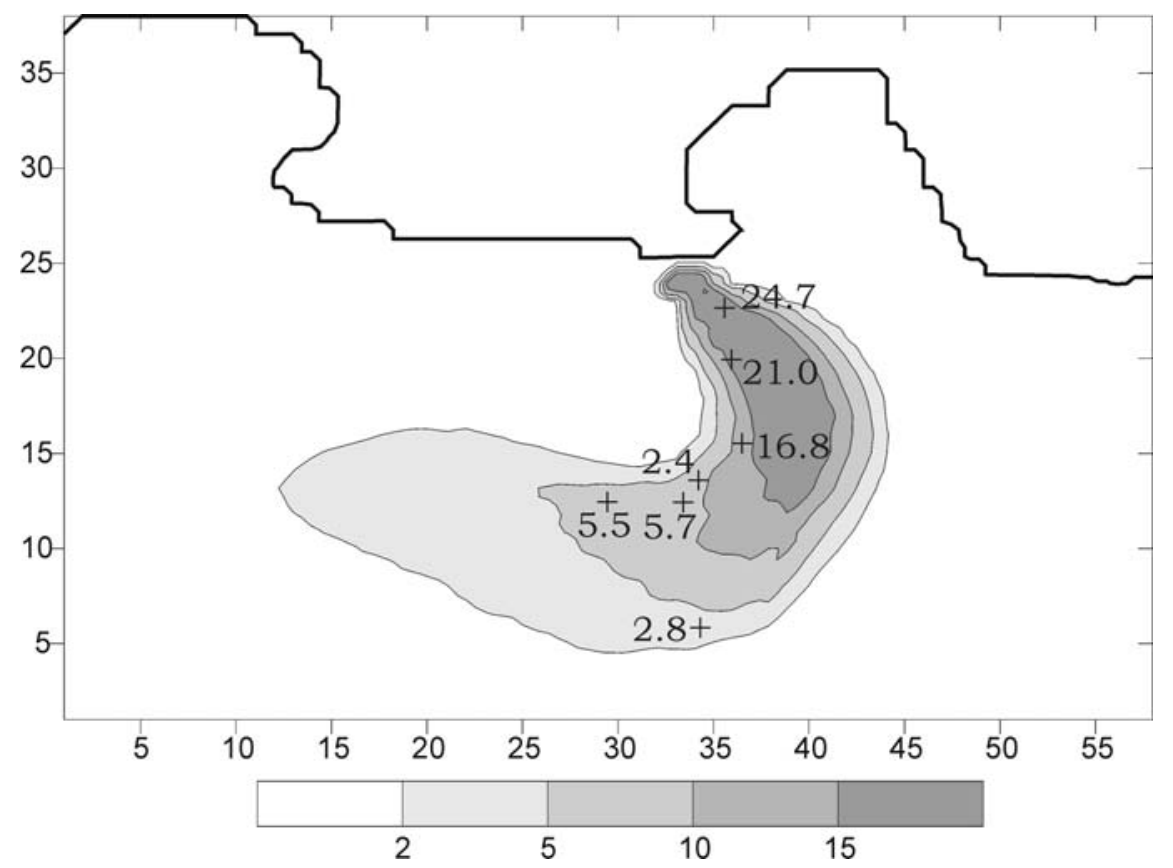

Figure 1. Computed and measured total suspended matter concentrations $(\mathrm{mg} / \mathrm{L})$ in the plume. Each unit in the axis denotes the grid cell number, thus is equal to $1 \mathrm{~km}$.

The computed distribution of ${ }^{137} \mathrm{Cs}$ in bed sediments is presented in figure 2, together with observations obtained from (6). It can be seen that the model gives a correct estimation of activity levels in the vicinity of the river mouth, although it underestimates them away from the river mouth. It must be taken into account that sediments integrate radionuclide input variations over time. Also, episodes of high river discharge, when larger amounts of particles are released to the sea and are also 
transported to greater distances from the river mouth, as well as different wind conditions, are integrated in the measured concentrations. Computed concentrations are obtained for average water, suspended particles and radionuclide discharges. It is not possible to have a accurate agreement between measurements and computations with a model working in average conditions. Nevertheless, it seems clear that the model produces rather realistic activity levels in the area of the river mouth. Indeed, the distribution map in figure 2 is very similar to that presented in (8), where a sharp decrease in inventories with distance from the river mouth can be seen. Finally, it must be taken into account that measured bed concentrations include deposition from global fallout. Only sampling stations close to the river mouth in (8) present ${ }^{137} \mathrm{Cs}$ inventories clearly in excess with respect the cumulative deposit due to global fallout (Chernobyl is not considered since it occurred later than the time of our simulations). Thus, most of ${ }^{137} \mathrm{Cs}$ in sediments appears in a well-delimited zone in the close vicinity of the river mouth. Our simulations are in agreement with these findings.

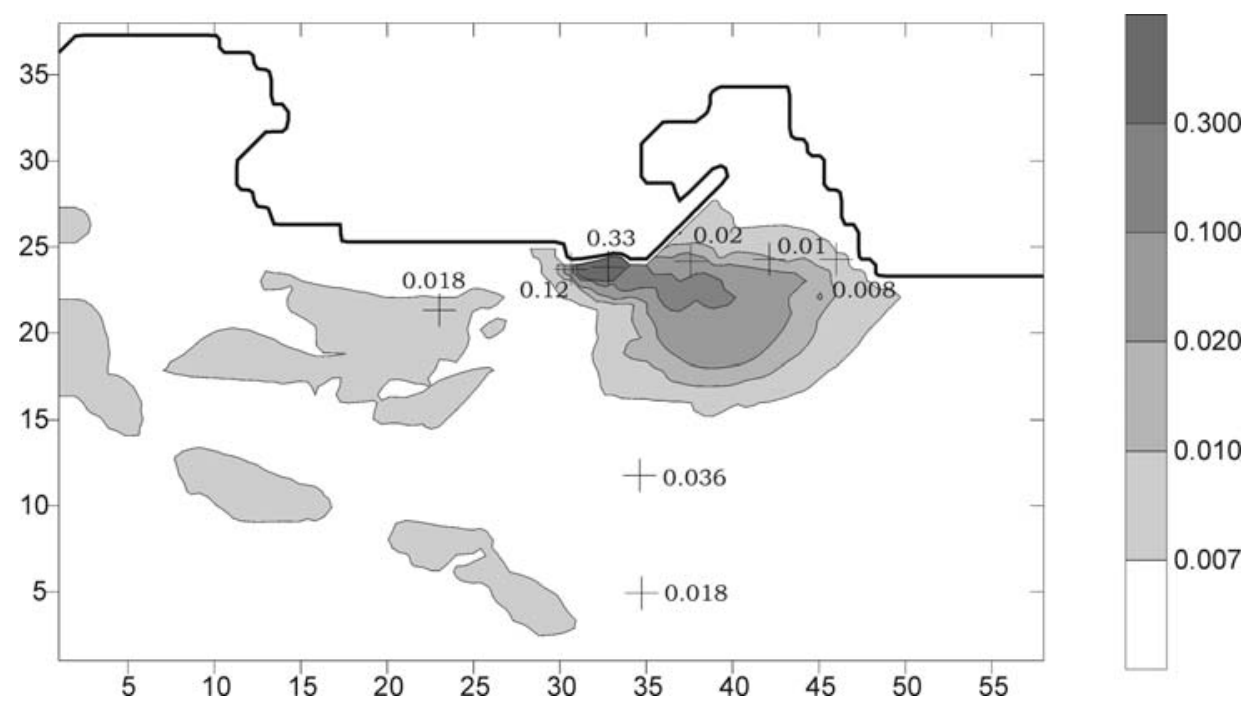

Figure 2. Computed and observed (6) ${ }^{137}$ Cs concentrations in bed sediments (Bq/g).
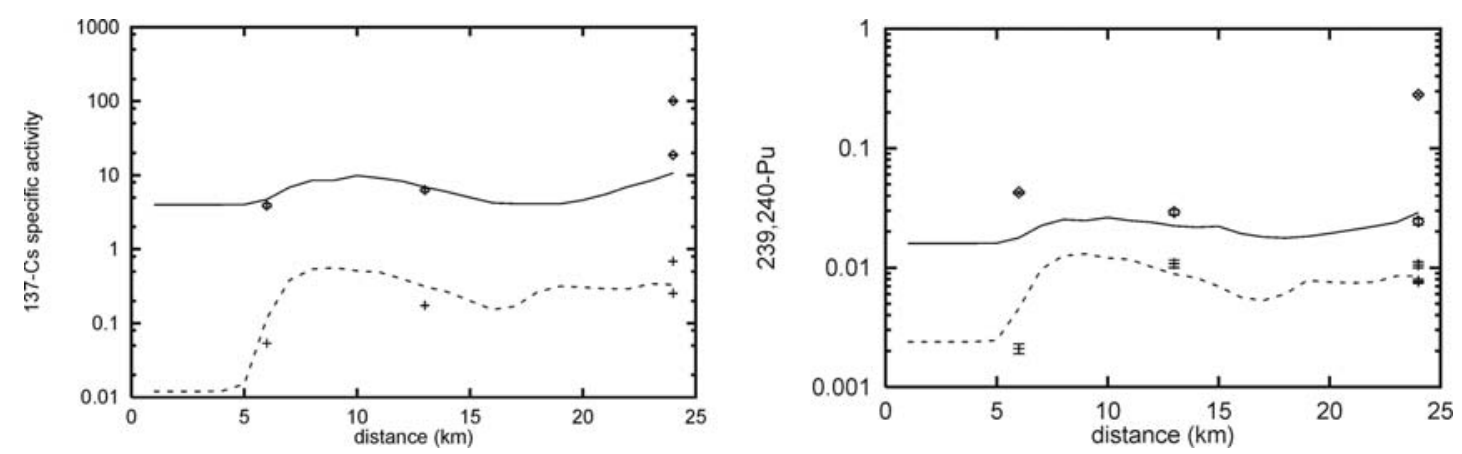

Figure 3. Measured (points) and computed (lines) concentrations of ${ }^{137} \mathrm{Cs}$ and ${ }^{239,240} \mathrm{Pu}$ in water (solid line, $\mathrm{Bq} / \mathrm{m}^{3}$ ) and suspended matter (dashed line, $\mathrm{Bq} / \mathrm{g}$ ) in front of the river mouth. Distances are measured from the south of the model domain. The river mouth is at $\mathrm{km} 24$. Measurements are taken from (6).

Computed Cs and Pu concentrations in the dissolved phase and suspended matter are compared with observations in figure 3, where south-north profiles in surface waters in front of the river mouth are shown. It can be seen that the model gives a correct representation of activity levels detected in the plume for both phases and radionuclides. 
The model can also give a wide amount of information, as fractions of radionuclides in suspended matter (for total suspended matter and each particle class) and distribution coefficients for suspended matter-water and bed sediment-water systems (as well for the total solid phase and each particle class). It is interesting to point out that the model calculates distribution coefficients instead of requiring them as input data. As an example, the computed fractions of $\mathrm{Cs}$ and $\mathrm{Pu}$ fixed to suspended particles in the plume are presented in figure 4 . It can be seen that over $60 \%$ of Cs and $90 \%$ of Pu are fixed to the solid phase. It has been measured that ${ }^{137} \mathrm{Cs}$ associated with particles represents $68 \%$ of the total (9). Similarly, Eyrolle and Charmasson (10) have reported that $85 \%$ of Pu isotopes are bound to particles. Thus, model results are in agreement with observations.
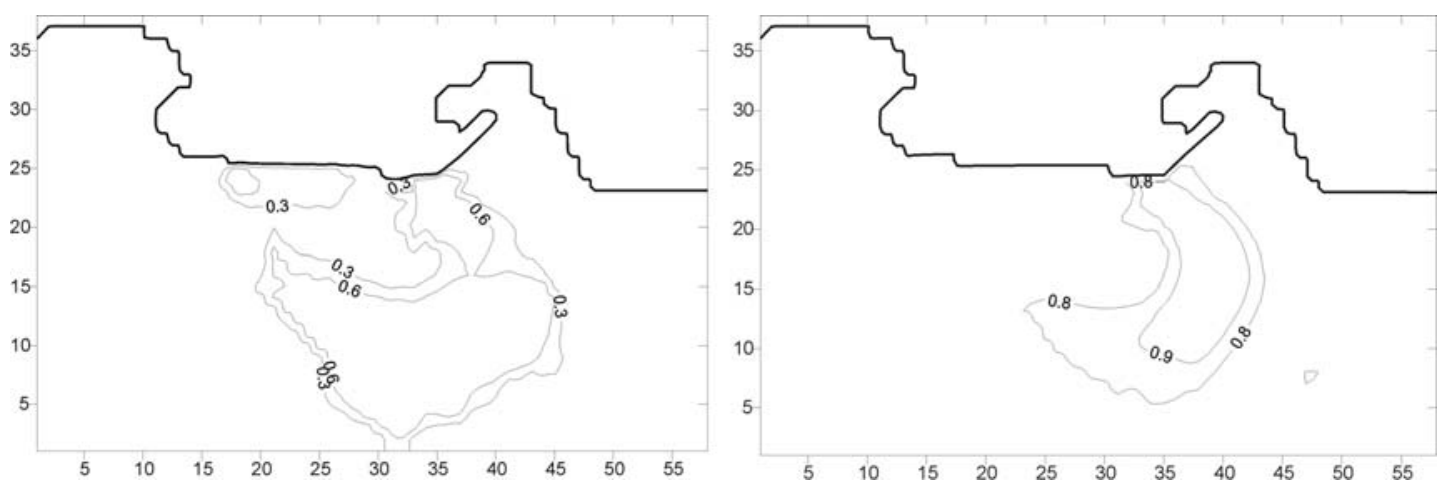

Figure 4. Computed fractions of Cs (left) and Pu (right) in the surface plume fixed to the suspended matter phase.

Finally, vertical profiles, in front of the river mouth, of plutonium in water and total suspended matter (both in $\mathrm{Bq} / \mathrm{m}^{3}$ ), can be seen in figure 5 . The suspended matter profile is clearly different to that of ${ }^{137} \mathrm{Cs}$ (not shown). In this case, it can be appreciated, together with the surface plume, a deep layer with some $\mathrm{Pu}$ content. This deep layer appears due to the higher reactivity of plutonium (in the case of ${ }^{137} \mathrm{Cs}$ only the surface plume is evident). It is composed of the coarse particles that sink quickly after they are released from the river. When these contaminated particles penetrate the bottom waters (not contaminated by Pu discharged from the Rhone), plutonium is partially redissolved. This leads to the sub-surface layer of contaminated water that can be seen in figure 5. Indeed, Eyrolle and Charmasson (10) have detected some Pu coming from Marcoule discharges in the bottom waters of the mixing zone.
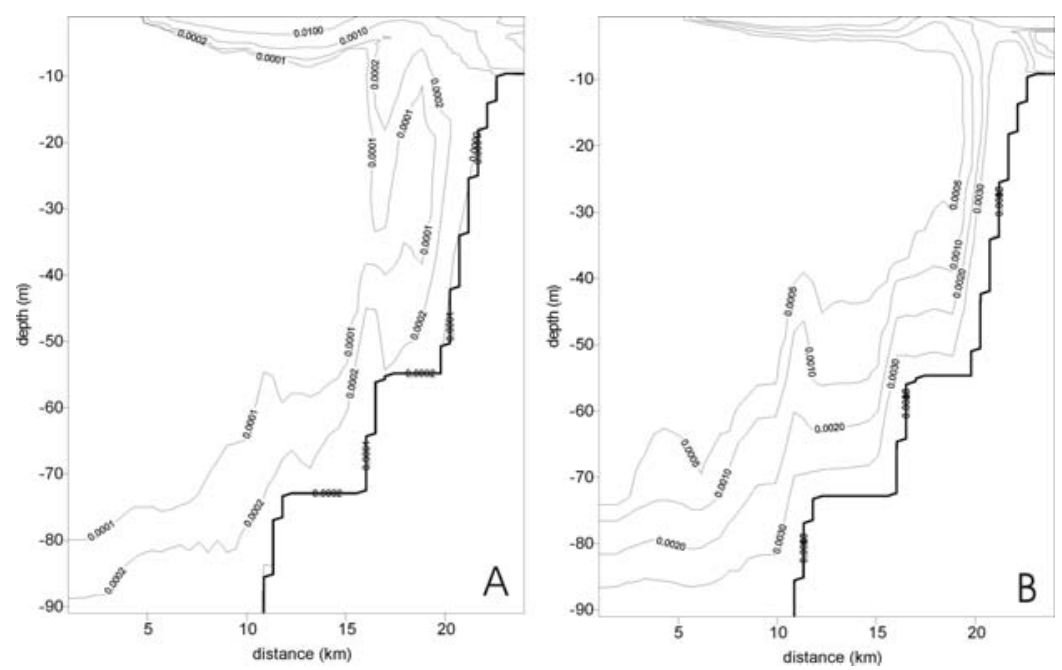

Figure 5. Computed ${ }^{239,240} \mathrm{Pu}$ activity in total suspended matter (A) and water (B), both in $\mathrm{Bq} / \mathrm{m}^{3}$, for a south-north vertical profile in front of the river mouth. 


\section{Acknowledgement}

Work supported by the EU Remotrans Project ( $5^{\text {th }}$ Framework Programme, contract FIGE-CT-2000-00085).

\section{References}

[1] R. Periáñez. Journal of Environmental Radioactivity 73 (2004), 101-115.

[2] R. Periáñez. Environmental Pollution (in press).

[3] R. Periañez. Journal of Marine Systems 22 (1999), 37-51.

[4] A. Laissaoui, J.M. Abril, R. Periáñez, M. García-León, E. García-Montaño. Journal of Radionalytical Nuclear Chemistry 237 (1998), 55-61.

[5] R. Periáñez. Journal of Environmental Radioactivity (in press).

[6] J.M. Martin, A.J. Thomas. Journal of Environmental Radioactivity 11 (1990), 105-139.

[7] J.J. Naudin, G. Cauwet, C. Fajon, L. Oriol, S. Terzic, J.L. Devenon, P. Broche. Journal of Marine Systems 28 (2001), 203-227.

[8] S. Charmasson. Oceanologica Acta 26 (2003), 435-441.

[9] D. Calmet, J.M. Fernandez. Continental Shelf Research 10 (1990), 895-913.

[10] F. Eyrolle, S. Charmasson. Journal of Environmental Radioactivity 72 (2004), 273-286. 